\title{
Ein Land, wo Milch und Honig fliesst.
}

H. Usener hat in einem sehr instructiven, der Beachtung der a.-t. Fachgenossen und der Kirchenhistoriker zu empfehlenden, Aufsatz: "Milch und Honig"r im Anschluss an Ausführungen in seinen Sintfluthsagen auch

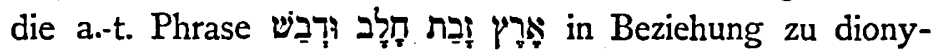
sischem Cult und $z u$ den Mythen vom Götterland und Paradies gesetzt. Die alttestamentlichen Theologen haben bisher wahrscheinlich allgemein unter dem Ausdrucke ein, vom Nomadenstandpunkt aus betrachtet, an schönsten Speisen besonders reiches Land sich vorgestellt. Denn die Beduinen sind noch mehr als andere Orientalen Liebhaber von Süssigkeiten. Und Milch ist die einzige Nahrung, die sie wenigstens für einige Monate des Jahres, so lange nämlich die Herden in Milch stehn, in Hülle und Fülle zur Verfügung haben. Es wäre dann ein kürzerer Ausdruck für die Aufzählungen der Producte des heiligen Landes wie wir sie Dt 8, 8. $\mathfrak{j}^{2}$, I3f. lesen. Die erste Stelle enthält unter allerhand anderen Nahrungs- und Genussmitteln den Honig, die zweite Milch und Honig. Die von H: Usener beigebrachten Parallelen sind jedoch so schlagend, dass man seiner Deutung der Phrase auf eine mythologische Vorstellung folgen wird, wenn sie sich mit dem alttestamentlichen Thatbestand in Einklang bringen lässt. Denn die

I Rhein. Mus. f. Philol. N. F. LVII, S. 177-192.

Zeitschrift f. d. alttest. Wiss. Jahrg. 22. II. Ig02. 
Annahme, dass auf zwei verschiedenen Gebieten menschlicher Cultur dieselbe Phrase aus verschiedenen Vorstellungen erwachsen sei, hat ihre Schwierigkeiten.

Prüft man die Stellen, in denen die Phrase vorkommt, so ergibt sich aus ihnen wenigstens keine Instanz gegen Usener's Deutung. Keine von ihnen kann mit Sicherheit für älter gehalten werden, als die Zeit des Synkretismus und der assyrischen Herrschaft (8. und 7. Jahrh. v. Chr.), in der mit Culten des assyrischen Reiches auch assyrischbabylonische Mythen, darunter die vom Paradies, und was damit zusammenhängt, eingewandert sein werden. Dass aber nur an Einwanderung aus diesem Bereich gedacht werden kann, folgt daraus, dass wir für die Sintfluth- und Paradiessagen an ihn denken müssen. Die ältesten sicher datierbaren Stellen, an denen die Phrase ובת חלב ודבש vorkommt, sind Ez 20, 6. 15. Die Stelle Jer 32, 22 ist sicher secundär (Gesch. des Volkes Israel S. 647 A.). Gegen Jer II, 5 hat neuerdings Duhm Bedenken erhoben. Ist sie echt, so ändert das aber nichts an der Sachlage. Nun weist man die Phrase wie gewöhnlich schon dem Jahvisten zu. Aber dass an dem Conglomerat, das man J nennt, wie auch an $\mathrm{E}$ bis ins 7. Jahrh. geschrieben worden ist, beweisen ja die Mythen babylonischer Herkunft in J. Und für E, aus dem einige Stellen mit der Phrase ובת חלב ודבש von den Kritikern hergeleitet werden, folgt die gleiche Annahme aus Gen 23, falls nicht auch in Gen 2.3 neben einer jahvistischen eine elohistische Parallele steckt, und sich hieraus יהוה אלהים und der Lebensbaum neben dem Baum der Erkenntniss erklärt. Wichtiger noch ist, dass die eigentliche Grundlage von J, die Patriarchensagen oder die Localsagen der alten Heiligthümer, die Phrase nicht enthält, wiewohl bei der Landverheissung dazu Gelegenheit gegeben war, sie anzuwenden. Sie taucht mit der Ausführung aus Aegypten auf und steht in den Penta- 
teuchstellen wie in den citierten Stellen der Bücher Jeremia und Ezechiel immer in Beziehung zu dieser Situation. Dem Lande Aegypten und der Wüste wird damit Kanaan entgegengesetzt. Ferner ist $\mathrm{zu}$ beachten, dass alle Stellen von JE mit der Phrase ובת חלב ודבש in stark durchredigierten Abschnitten stehn Ex 3, 6. I7 Num I3, 27. I4, 8. I6, I3 f. Die Phrase begegnet auch sonst in redactionellen Stellen Lc 20; 24. Jos 5, 6 und ist insb. deuteronomistisch Dt 6,3 . I I, 9. 26, 9. I5. $27,3.3$ I, 20.

Kanaan ist ein Land des Weinbaus und dionysischer Culte. Der Wein, ursprünglich ohne jede Beziehung zu Jahve und seinem Culte wie das Nasiräergelübde zeigt, hat sich in den Jahvecult gedrängt und trotz Anfechtungen in ihm behauptet. $\mathrm{Ob}$ es freilich mehr als Zufall ist, dass die Kundschafter die Phrase gebrauchen, während sie die grosse Traube vorweisen $\mathrm{Nu}$ I3, 27, wage ich nicht $\mathrm{zu}$ entscheiden. Sie bringen ja auch Granatäpfel und Feigen mit.

Dass auch der Gebrauch des Honigs als Opfergabe aus einem palästinischen Culte in den Jahvecult zeitweilig eingedrungen aber wieder ausgeschaltet worden ist, wird man aus $\mathrm{Ez}$ I6, I9. Lv 2, I I. $2 \mathrm{Chr}$ 3I, 5 schliessen müssen. Es ist ihm nicht wie dem Wein sich zu behaupten gelungen.

Von Milch und Honig wird aber ,Dickmilch (חמהז) und Honig". zu scheiden sein. Das alte Orakel des Jesaia 7, I-14. 16 hat in v. $18-20$ und v. $21-25$ zwei Nachträge erhalten. Die Naht durch die v. I8-20 angefügt wird ist v. I7. Dagegen ist v. I5 die Naht von v. $2 \mathrm{I}-25$. Sonach ist bei der Erklärung von „Dickmilch und Honig" von 7, 22 und nicht von 7, 15 auszugehn. 7,22 bezeichnet aber beides deutlich als eine Nahrung, die man unter nomadischen Verhältnissen Kindern reicht, vgl. Ez 16, 13.

Dass in christlicher Apokalyptik zur Ausstattung des himmlischen Jerusalem Quellen oder Ströme von Milch und 
Honig gehören', geht, wie Usener mit Recht annimmt, auf hellenischen nicht auf jüdischen Einfluss zurück ${ }^{2}$. Denn die Phrase ist in den messianischen Sprachgebrauch des A. T. nicht cingedrungen. Es ist das um so bemerkenswerter, als nach Joel 2, 18 die Hügel in der messianischen Zeit von Most und Milch, nach Am 9, 13 von Most triefen sollen.

Sind die vorgetragenen Erwägungen richtig, so steht man vor der Frage: „Kommt die mythologische Idee von Milch und Honig als Götterspeise oder Kost des Götterlandes in den assyrisch-babylonischen Mythen vor?" Vielleicht, dass die Assyriologen die Frage beantworten können.

I Usener citiert 4 Esr. 2, 19 und die apokryphe Apocalypsis Pauli 23 ff., Apocalypses apocryphae ed. Tischendorff, p. 52 ff., lateinisch: Text and Studies ed. by A. Robinson II, 3, p. 24. 25. Parallelen.

2 Man vergleiche zum Belege die von $H$. Usener angeführten B. Stade. 